\title{
O loga e os seus Novos Bens de Salvação: Relaxamento Espiritual e Homeostase Divina ${ }^{1}$
}

\author{
Yoga and its New Salvation Goods: \\ Spiritual Relaxation and Divine Homeostasis
}

Roberto Serafim Simões ${ }^{2}$

RESUMO

\begin{abstract}
A fase moderna do ioga está sendo erigida por influência de um novo contexto socialreligioso. Atualmente, muito mais do que brâmanes e swamis, o ioga busca a sua legitimidade como caminho espiritual sob a égide da racionalidade científica e de novos movimentos religiosos do ocidente. Nesse processo, o ioga ressignifica a sua linguagem mística, que circulava entre os ashrams e florestas indianos dos tempos antigo e medieval, para um público que enfrenta os desafios estressantes de se viver nos grandes centros urbanos ocidentais, sobretudo, uma sociedade do consumo, secular e privatizada religiosamente. A partir dessa conjuntura novas crenças despontaram para legitimar 0 discurso do ioga frente ao panorama social-religioso em que ele vive atualmente. Mais do que simples ressignificação simbólica, a soteriologia ioguica moderna está passando hoje por um processo de reforma soteriológica. As principais transformações que se destacaram, estão: 1) na elevação da concepção de estresse ao nível de kleśa ou obstáculo espiritual; 2) o relaxamento, antagônico ao estresse-kleśa, conquista de natureza espiritual; e 3) por consequência, a libertação/salvação dos kleśas-estresse adquirem substância "empírica" de estado místico como uma espécie de "homeostase divina".
\end{abstract}

PALAVRAS-CHAVE: ioga, fisiologia, kleśas, salvação espiritual, relaxamento, estresse.

\begin{abstract}
The modern phase of yoga, therefore, has been built under the influence of a new socialreligious context. Currently, a lot more than brahmins and swamis, the yoga searches for legitimacy as a spiritual way by the aegis of scientific rationality and of new religious movements in the occident. In this process, yoga reframes its mystic language that circulated among Indian ashrams and forests in ancient and medieval times, for the public that faces stressful challenges to live in occidental megacities, above everything, a consumer society, secular and privatized religiously. From that conjecture, new beliefs emerged to legitimise the yoga discourse in the social-religious panoram where it currently lives. More
\end{abstract}

\footnotetext{
${ }^{1}$ Recebido em 30/05/2017. Aprovado em 30/09/2017.

2 Doutor em Ciência da Religião pela PUC-SP. Email: iogacontemporaneo@gmail.com
} 
than simple symbolic reframes, the modern yogic soteriology is today passing through a process of soteriological reframes. The main transformations that are highlighted, are: 1) an elevation of the conception of stress at the level of the kleśa or spiritual obstacle; 2) relaxation, the inverse of the stress-kleśa, conquests the spiritual nature; and 3) as a consequence, liberation/salvation of the kleśas-stress acquires the "empirical" substance of a mystical state, like a kind of "divine homeostasis".

KEYWORDS: yoga, physiology, kleśas, spiritual salvation, relaxation, stress.

\section{Introdução}

O ioga atualmente dialoga com a ciência biomédica e a educação física elevando o valor da saúde em detrimento a outros aspectos éticos de sua doutrina. Algumas pesquisas apontam inclusive uma nova tipologia de iogues surgindo, o que indica inovações sobre o papel do ioga em sociedades modernas: seja de um iogue mais pragmático ou cientista que compreende a sua prática apenas como técnica profilática e de condicionamento psicofísico, até iogues místicos convictos que Deus - ou algo similar - e ele são Um. Além da ciência, o ioga desde o início do século passado vem também sincretizando muitos de seus princípios hinduístas com o jainismo e o budismo durante o seu período histórico medieval na Índia, assim como por movimentos religiosos denominados Nova Era desde a virada do século passado. No Brasil especificamente, o ioga vem se imbricando com expressões católicas, espíritas, daimistas e umbandistas.

Em complexas sociedades modernas a secularização, ao invés de diminuir crenças com base no sobrenatural, vem autorizando, através da privatização religiosa, novas espiritualidades a ingressassem no campo religioso mundial, disputando a hegemonia com as antigas dominantes (WEBER, 2001; BOURDIEU, 2011, p.79-98). Assim, práticas rituais e concepções místicas e mágicas antes incorporadas exclusivamente no seio de religiões já institucionalizadas - como o ioga no 
Hinduísmo, o tai-chi chuan no Taoísmo ou a cabala no Judaísmo - foram transplantadas do oriente para o ocidente, mas ornadas como terapias espirituais (HANEGRAAFF, 1999), associadas ao movimento religioso mais amplo que [CHAMPION, 1989) as permitiu sobreviver ao desencantamento do mundo (HANEGRAAFF, 2003). Assim, qualquer alteração no contexto sociocultural de uma dada denominação religiosa suscitará mudanças em sua estrutura de conhecimento do mundo, e com o ioga não está sendo diferente.

O ioga, antes um darśana ou "escola filosófica" hinduísta ortodoxa, parece revelar-se hoje um misto de terapia biomédica e aula de ginástica na qual a ciência, mais do que qualquer outra religiosidade institucionalizada, mostra-se legitimadora do seu discurso em sociedades modernas (ver ALTER, 2004). Até o Ministério da Saúde brasileiro discute a inclusão do ioga em seu Sistema Único de Saúde (SUS) ${ }^{3}$, e discussões sobre o papel do ioga como prática médica não-convencional são debatidas acadêmica e politicamente no país (SIEGEL, 2010). A esta altura, seria lícito supor um ioga sendo praticado destituído de suas singulares características religiosas, como ocorreu com a acupuntura, haja vista a difusão indistinta de crenças antigas ioguicas com outras espiritualidades, mas sobretudo, pela inclusão dos seus ritos corporais em laboratórios científicos e hospitais. Em outras palavras, em ambientes (aparentemente) laicos e seculares, aonde conceitos transfisiológicos como prāṇa, kunḍalinī, nāọīs e cakras, assim como, éticas espirituais e experiências místicas não teriam o menor interesse - kleśas e samādhi, especificamente. No entanto, não é isso que parece ocorrer, e alguns pesquisadores já apontam o ioga como uma nova religião em andamento, sobretudo em cidades modernas, com foco em suas práticas rituais corporais de cura (DeMICHELIS, 2004; JAIN, 2014; FIELDS, 2001).

\section{Soteriologia ioguica clássica}

Para adentramos nesta discussão sem nos perdermos em terminologias em sânscrito e questões filosóficas sobre a sua espiritualidade, escolhemos apresentar, mesmo que de forma sucinta e inicial, a soteriologia considerada "tradicional" ou

3 http://www.saude.es.gov.br/download/SESA_MANUAL_PIC_VERSAO_FINAL.pdf, acessado em $01 / 10 / 2014$. 
antiga do ioga, e a confrontar com as possíveis alterações acolhidas no seu contato com a cultura moderna ocidental, na configuração do que muitos investigadores denominam hoje de ioga postural moderno (DeMICHELIS, 2004). Abaixo descrevo alguns aforismos (sūtras) de uma das mais conhecidas e propaladas escrituras ioguicas, o Yoga (loga) Sūtra (IS, daqui em diante), para nos auxiliar sobre as possíveis alterações sobre o conceito de kleśa como causa iogue do sofrimento humano:

1.2. Yoga é a supressão dos movimentos da consciência [ou citta vrttis nirodha].

2.2. Com o propósito de produzir a integração [samādhi] e também com o propósito de tornar tênues as aflições [kleśas ou obstáculos espirituais].

2.3. As aflições [kleśas] são: ignorância, sentido de autoafirmação, desejo, aversão e apego à vida.

2.25. Da inexistência desta ignorância [avidya], resulta a conjunção [samādhi]: esta é a revogação do problema, o isolamento (kaivalya), no absoluto, do poder de ver.

2.29. Refreamentos [yamas], observâncias [niyamas], postura [āsana], controle do alento [prānāyama], bloqueio das interações [prathyahara], concentração [dhārana], meditação [dhyāna] e integração [samādhi]: estes são os oito componentes do Yoga [ou așthāniga ioga, o caminho espiritual óctuplo] [GULMINI, 2002, p.115-262).

Mesmo compreendendo não ser aqui o local acadêmico para realizarmos uma exegese das escrituras ioguicas, julgo ser pertinente esclarecer melhor os seus significados. Por isso, se faz necessário que se comente as suas passagens para uma maior compreensão posterior, aonde analisarei as possíveis reformas soteriológicas sofridas destes aforismos do ioga com o mundo moderno. Saliento, contudo, que tenho consciência de que muitos comentaristas modernos do Yoga Sūtra (IS), especialmente brâmanes e acadêmicos europeus do início do século XX, intentaram adequá-lo ao pensamento racional do ocidente, destituindo-o, em parte, de sua linguagem mística e mágica para uma racionalidade mais condizente com $\mathrm{O}$ pensamento acadêmico (SARBACKER, 2008, p.165; SINGLETON, 2008, p.77-99). 
O ioga de Patanjali descrito no IS, possui um ponto de vista dual da realidade. O corpo (prakrti) e a alma (purușa), portanto, são irreconciliáveis. É a "consciência" (citta] $^{4}$, por meio dos "órgãos sensitivos" (indrīyas), que estabelece o rompimento dos homens e mulheres com a perenidade harmônica de citta-purușa. $\bigcirc$ iogue crê que a alma exista em um estado de "não-movimento" ou "harmonia perene", denominado em suas escrituras como samādhi, no qual a alma e a consciência experienciam uma Bem-aventurança divina constante (ARANYA, 1983, p.22; BERRY, 1992, p.82-87).

O IS esclarece que a dificuldade de se restabelecer ao estado harmônico divino primordial reside nas condutas impuras que se comete deliberadas pelos comportamentos associados aos kleśas (lit. aflição) (SARBACKER, 2008, p.165). No sūtra 2.25 nos é apresentado o "Kleśa-mãe" ou responsável vital por todo o sofrimento humano: a ignorância ou a ausência de conhecimento dos indivíduos em não se reconhecerem já livres de toda e qualquer dor ou angústia existencial (ARANYA, 1983, p.122). Os outros kleśas ou causas das aflições ou mal-estar são revelados no sūtra 2.3 como "filhos da ignorância" pelos comportamentos de apego, aversão, medo da morte e a falsa identidade/orgulho. Os iogues, ao contrário dos cristãos por exemplo, acreditam que numa condição originária de pureza e harmonia; mas no contato com o mundo e desatentos, ou alienados de sua natureza estável de Bem-Aventurança, criam um ciclo nocivo de sofrimento e "confusão mental" (cittaṿttis) na identificação do corpo e da consciência com o mundo.

Estudos mostram que as diferenças que caracterizam a passagem do ioga tradicional para o moderno residem na sua medicalização e, por conseguinte, na popularização dos seus ritos corporais em técnicas terapêuticas de combate ao estresse (DeMICHELIS, 2008, p.23-27). Essa transformação, ainda em processo, parece acontecer em algumas escolas ioguicas sem incorrer na perda total de sua espiritualidade.

Numa pesquisa realizada em Londres em 2002 com 750 praticantes de ioga, descobriu-se que $80-83 \%$ destes iogues compreendem as suas práticas tanto como auxiliares no combate ao estresse, quanto na experiência igualmente válida de uma

\footnotetext{
${ }^{4}$ Citta é formado pelo "intelecto" ou lit. perceber (buddhi), o "ego" ou lit. princípio individual (ahamkāra] e a "mente" ou lit. ato de pensar (manas).
} 
vida espiritual plena. Suzane Newcombe concluiu até mesmo ser possível classificar o ioga hoje como uma religião mística, segundo o conceito desenvolvido por Colin Campbell a partir de Ernst Troeltsch (NEWCOMBE, 2005). A relação que possa existir entre estresse e religião não foi incluída em suas perguntas, mas as suas descobertas ganham mais sentido quando a expomos a um dos pensamentos de B.K.S.lyengar, o líder espiritual da escola de ioga investigada por Newcombe e um dos iogues mais populares e respeitados do mundo. Segundo ele: "a pessoa indisciplinada é alguém sem religião; a pessoa disciplinada é religiosa; a saúde é religião; a doença é falta de religião" (IYENGAR, 2001, p.38). O seu discurso associado a nossa argumentação até aqui nos direcionam a concluir haver uma estreita relação se estabelecendo entre a biomedicina e o ioga moderno, que ao invés de desencantá-lo, pode estar legitimando-o como uma nova religião.

Mesmo que escassos, estudos brasileiros corroboram essa afirmação do ioga no Brasil. Pesquisas revelam que o ioga vem perdendo o seu atributo de errância que predominam em espiritualidades Nova Era (NUNES, 2008), exprimindo que os iogues brasileiros tem se tornado mais fiéis ao seu guru ou professor de "formação". Ao mesmo tempo, o ioga já desperta discussões sobre o seu papel social, seja de terapia ou ginástica laicas (FERNANDES \& DA ROCHA, 2005), chegando até mesmo a se defender sua independência do Conselho Federal Brasileiro de Educação Física. Tal fato favoreceria a afirmação do seu caráter vivo de sincretismo com a religiosidade brasileira, fomentando algum tipo novo de espiritualidade (GNERRE, 2010).

processo de secularização e privatização religiosa pode estar refletindo na relação do ioga com as ciências da saúde. Essa, ao invés de extinguir a religiosidade ioguica, torna-se responsável por suscitar novos problemas e soluções religiosas que não seriam possíveis em outros termos. $\bigcirc$ ioga, antes subordinado a religião hinduísta e recentemente às terapias espirituais de novos movimentos religiosos Nova Era, vem adaptando-se ao racionalismo da ciência e a agitação dos grandes centros urbanos consumistas, utilizando as descobertas empíricas de promoção de relaxamento físico e atenção mental das pesquisas em fisiologia biomédica sobre as suas práticas rituais para reformar a sua antiga teoria dos kleśas como causa do sofrimento humano, e produzir novos bens de salvação. $\bigcirc$ objetivo central aqui 
estará em compreender a transformação dos kleśas no ioga moderno em dialética com a ciência biomédica e a sua religiosidade contemporânea.

\section{Teoria dos kleśas corporificada: sinônimo de estresse e emoções}

lyengar, um dos iogues modernos mais influentes nas sociedades contemporâneas, descreve no capítulo Bem-Aventurança: O corpo divino, do seu livro Luz na Vida: A jornada do ioga para a integridade, os kleśas com sensíveis transformações ontológicas. Uma das primeiras influências que se percebe na nova configuração em andamento está em relação as referências utilizadas para comentar os Kleśas. não mais os textos contidos no Hinduísmo, mas por meio de parábolas cristãs e artigos científicos da biomedicina. lyengar (2007, p.188) se utiliza de uma parábola de Jesus para explicar o sentido do kleśa-mãe, a Ignorância:

O Senhor Jesus explica isso bem (a Ignorância). Ele disse que se você construir a sua casa na areia, isso vai ceder. Se você construir ela na rocha, vai ficar firme. Isso significa que a vida precisa ser erigida em uma fundação firme da realidade. Infelizmente, o que parece firme, isto é, as coisas da vida que nos oferecem segurança, riqueza, posses, preconceitos, crenças, privilégio e posição, não são sólidos em tudo. Que remete para quando eu disse que aprender a viver com a incerteza é a grande arte de viver. Jesus também quis dizer que, somente uma vida construída sobre valores espirituais estará baseada firmemente na verdade e vai se manter de pé até aos choques da vida.

Em outro livro, lyengar apresenta os kleśas como forças do mal inatas nos seres humanos no qual as sociedades ocidentais associam ao Demônio, ele diz. $\bigcirc$ Mal/demônio/ kleśas seria responsável por causar as "flutuações da consciência" que, por fim, originariam toda a sorte de sofrimento ou de uma "vida ignorante de si mesmo". Conduzir a vida baseada na ignorância de si mesmo é, segundo as escrituras ioguicas, viver sob a égide do Medo da morte, do Apego, da Aversão e do Orgulho, os denominados Kleśas. Nas palavras de lyengar, viver no Mal/demônio/ kleśas é como construir uma casa na areia, parafraseando a parábola de Jesus. E continua, o "demônio no ioga" (Kleśa) é alienado ou alienante: "Ele [kleśa] é ignorante. Na verdade, ele é a Ignorância dele mesmo. Para os hindus, o arquinimigo é o estado do não-conhecimento" (IYENGAR et.al., 2005, p.190). 
Para explicar os kleśas, lyengar também se utiliza de comparações fisiológicas científicas com a saúde e áreas encefálicas específicas. $\bigcirc$ kleśa Medo da morte, por exemplo, possui existência, acredita, em nível psicobiológico e corresponde aos lobos posteriores do cérebro:

Abhinivesa (medo da morte) é um instintivo apego a vida. Abhinivesa pode facilmente ser experienciado se você prolongar bastante a retenção no fim da exalação. $O$ pânico se instala. Isso é ignorância, ou um equívoco fundamental da Realidade, que sustenta e alimenta todas as outras aflições (IYENGAR et.al., 2005, p.199).

A Ignorância (avidyā) e o Orgulho (asmitā), possuem correlação aflitiva na porção encefálica da "inteligência" (Ibid., p.196): "Aqui a falta do conhecimento espiritual combinado com orgulho ou arrogância inflam o ego, causando presunção e a perda do senso do eu em harmonia". O kleśa Apego (rāga) produz na mente o desejo, enquanto o Kleśa Aversão, (dveșa), ódio. Esses kleśas, segundo lyengar:

Produzem uma desarmonia entre o corpo e a mente, nos quais podem originar desordens psicossomáticas. (...) E ambos os kleśas, possuem correspondentes cerebrais no hipotálamo (Ibid.).

lyengar conclui em sua análise moderna aos kleśas, que "devemos manter o nosso corpo tão saudável quanto possível no caminho espiritual", pois na doença nós esquecemos nossos corpos e os Kleśas, constantemente modificados pelos estímulos sensoriais, causam flutuações em nossos ciclos respiratórios e consciências - portanto, ao fluxo prânico (ou energia vital) - corrompendo nossas vidas e viciando nossas melhores intenções.

○ que sublinhei nas duas citações de lyengar anteriores (harmonia e desarmonia) é crucial para o nosso entendimento da reforma em andamento das causas do Mal/ Kleśas no ioga contemporâneo. Há uma tendência entre os iogues modernos em associar os antigos conceitos transfisiológicos do ioga (prāṇa, chackras, nadis e etc) com os da fisiologia biomédica; entretanto, não ocorre uma simples ressignificação, mas uma reforma soteriológica em como os iogues atuais os sentem, percebem e, portanto, vem construindo novas estratégias de combater o Mal/ kleśas, por isso afirmo que uma nova proposta de salvação ioguica vem sendo erigida na transplantação do ioga indiano medievalista para o mundo moderno. 
Os kleśas como Mal para lyengar, por "agitar a consciência", influem na harmonia da transfisiologia ioguica pois bloqueiam o livre fluir de prāna e, por isso, favorecem uma maior manifestação de doenças. Em última instância, o samādhi - o estado místico ioguico - tece relação com ambos (kleśas-prāṇa) pois só é possível atingi-lo [samādhi ou "iluminação"] em perfeita harmonia, ou seja, no cessar do "agitar da consciência" - ou cittavrtti-nirodha.

O ioga moderno, desse modo, vem estabelecendo um diálogo entre saúdesalvação, e as doenças como manifestação física do samādhi, tecem correspondência empírica Kleśa-estresse-doença, como veremos. Não é coincidência ocorrer a medicalização do ioga nas sociedades modernas, aonde as suas práticas surgem como terapias espirituais. $\bigcirc$ ioga como uma nova espiritualidade terapêutica reforma seus bens de salvação, aonde a sua fisiologia "sutil" ou transfisiologia, se ressignifica à luz da ciência fisiológica biomédica legitimando a doutrina moderna ao invés de promover o desencantamento das mesmas.

\section{Corporificação do Mal/ Kleśas}

Com a corporificação dos kleśas e a medicalização do ioga, percebe-se uma preocupação entre os iogues modernos em observar as reações psicofísicas na busca de reestabelecer certa harmonia fisiológica perene inata ou "homeostase divina". Mais do que a tradicional moral ioguica, como por exemplo, observância dos yamas e niyamas, a ética religiosa do ioga se privatiza e é transferida para o efeito (supra)sensorial que a prática corporal ritualizada produz (seja de uma aula com posturas, exercícios respiratórios e limpezas transfisiológicas, canto de mantras e/ ou mesmo leitura e estudo das suas escrituras junto ao mestre).

Ao que tudo indica, os rituais corporais do ioga moderno seriam como sistemas "purificadores" das forças nefastas dos Kleśas, ao mesmo tempo que solidificariam a vida ioguica na "rocha da verdade", parafraseando lyengar em sua analogia dos kleśas com a parábola de Jesus. Há inclusive um dos métodos/tradições de ioga mais populares no mundo, o Asthanga Vinyāsa Yoga, que se destaca por suas rígidas séries de posturas combinadas com a respiração (ujjay), contrações musculares específicas (bandhas) e saltos (os vinyāsas), na qual o objetivo está literalmente - e (trans)fisiologicamente também - em elevar o calor físico, para 
assim "eliminar substâncias nocivas ao corpo" através de tapas (lit. austeridade ou esforço sobre si mesmo). A orientação ritual é praticar com janelas e portas fechadas para suar mais ou produzir tapas como purificador. A expressão tapas, lit. significa austeridade, mas como deriva da palavra tap, pode exprimir "fornecer calor" ou ainda "fazer-se quente" (SMITH, 2008, p.143-150).

Tapas provê ao devoto um "calor na cabeça" [head heat], transformando-o em um vidente. De um modo semelhante, o esforço da prática ascética acende o "fogo interior" [inner fire] da iluminação, em uma visão de êxtase. Como o rsis [místicos hindus que escreveram os textos religiosos do hinduísmo], o asceta, através de tapas, é capaz de "ver". Neste contexto, tapas adquire a forma de um "meditar cognitivo" [cognitive brooding], ou "intensa meditação". O poder aqui empregado para tapas é claramente de "poder contemplativo" (KAEBLER, 1989, p.145-146)

Com o calor corporal gerado pela prática ritual ioguica, o praticante pode alcançar a iluminação/samādhi e ser capaz de "ver" como os místicos hindus tradicionais. Em outras palavras, para o ioga moderno, desde os hāṭhaiogues, o corpo vem adquirindo caráter não só de "templo divino", mas de referência de caminho espiritual e determinante no alcance do samādhi ou o estado de equilíbrio/harmonia/homeostase. Desse modo, o samādhi, como vivência do cessar do citta-vrttis (ou agitação mental), torna-se não somente de "cura de doenças", mas principalmente da purificação do Mal/ kleśas como resultado das práticas de corpo ritualizadas. Com a corporificação dos kleśas, a ética do ioga se desprende das crenças metafísicas de suas antigas escrituras, transformando a saúde em referência do Bem e a doença, sinônimo do Mal, portanto, dos kleśas em sensações e percepções corpóreas também.

Em outro artigo mais sofisticado, a filósofa da religião Anindita Balsev aproxima os kleśas aos conceitos da emoção. A sua análise nos permite compreender como a noção dos kleśas e samādhi pode estar atualmente atrelando a soteriologia do ioga ao corpo, aonde, como expusemos acima, suas práticas vem se transformando em rituais de cura e purificação para alcance da "iluminação" ou samādhi.

A autora nos lembra que um dos comentaristas mais famosos e citados do Yoga Sūtra (IS - doutrina clássica dos iogues), Vyasa, revela que o objetivo do ioga é 
diminuir as agitações da mente. No entanto, ele diz: "O rio chamado mente flui em duas direções" (BALSEV, 1991). E Balsev nos explica:

A imagem das "duas direções" transformam o fluxo da vida mental... As duas direções são primeiro caracterizadas como fluindo em direção ao bom e através do mal (vahati kalyaanaaya vahati papaayaca), pelos quais expressam primariamente uma consideração ética. (...) fluir em direção a discriminação (viveka] e isolamento/salvação (kaivalya) é bom, enquanto o que nos prende na existência neste mundo (samsara) é o mal, claramente indicando uma proposta soteriológica. (...) Esta metáfora da mente como um rio em duas direções, porém, adquire um significado técnico no Yoga-Sutras introduzindo uma divisão dos estados da mente, classificando-as em dois grupos: klista [ou kleśa/dor/Mal] e aklistavrtti [não-kleśa-vrtti/ não-sofrimento].

Em outras palavras, Balsev argumenta que a palavra kleśa é usada sempre como sinônimo de dukha ou sofrimento, mas que não é meramente o oposto de sukha ou prazer. O significado de kleśa é uma oposição à busca salvacionista/libertadora em direção ao rompimento do ciclo de samsāra ou renascimentos, de atingir o estado de kaivalya ou samādhi. Teríamos então uma busca pela salvação/iluminação não somente pela atenuação do apego, da aversão, do medo da morte e do orgulho, causados pela ignorância (os cinco kleśas portanto), mas pela busca dos seus opostos, ou aklișța-vrtti - o movimento da mente para longe do sofrimento causado pelos kleśas. Por isso, a autora busca os correspondentes emocionais dos kleśas para trabalhar com a ideia que certas emoções, portanto corporais, seriam nefastas por acorrentar os seres humanos na agitação maléfica das suas mentes e, por conseguinte, enredá-los no ciclo de samsāra ou vida de sofrimentos.

Balsev indaga sobre o surgimento dos kleśas. O IS afirma ser o kleśa Ignorância, a mãe de todos os outros kleśas. Deste modo, a filósofa argumenta que a aversão adviria das sementes da dor e da falsa cognição que certos objetos da mente, associados a dor, causariam sofrimento, e por isso nos manteríamos afastados, em aversão a eles. Os objetos mentais denominados de kleśzAversão estariam atrelados aos sentimentos de retaliação, de malícia, da vingança e do ódio; centros, deste modo, dos kleśas Apego e Aversão, onde o desejo e o prazer seriam os núcleos emocionais destes. Assim, a dupla Apego-Aversão poderiam ser desencadeadores 
dos sentimentos de nojo, raiva, medo e prazer e seus correspondentes efeitos psicofisiológicos, como veremos adiante.

Para a autora, o kleśa Medo da morte, incidiria sobre o corpo causando o temor angustiante em saber que se vai morrer, mas não quando. A angústia seria o sentimento corporal correspondente a este kleśa e "agitar" a mente iogue de forma nefasta. O kleśa-Senso do Eu ou Orgulho, estaria no erro de julgamento, segundo a autora. Ela pondera que o kleśa-Orgulho seria a base intelectiva para os três erros de julgamento anteriores (apego-desejo, aversão-ódio e medo da morte-angústia), pois tanto o desejo, quanto ódio ou o medo estariam centrados em nosso ego individual, que não percebeu ainda que se é purusa - o ser Imaculado ou essência, portanto, em equilíbrio e harmonia eternos, conforme a doutrina do ioga descreve. Por isso, a autora associa o kleśa-Orgulho ao sentimento do egoísmo.

Estas quatro aflições-kleśas (Apego-desejo, Aversão-ódio, Medo da morteangústia e Orgulho-egoísmo), comenta Balsev, não estão sempre presentes em suas formas totalmente manifestas. Em tom psicanalítico, continua, a descrição dos kleśas encontradas no IS 2:4, descrevem-nos de forma dormentes (prasupra), atenuados [tanu), interceptados (vichinna) e manifestos plenamente (udāra). Este é, de fato, um aspecto significativo da análise dos kleśas no ioga em conexão com a perspectiva corpórea-emocional que a filósofa conduz em sua argumentação:

A mente, como o Yoga o vê, é naturalmente atraída em direção a samsara [leia-se ciclo reencarnatório, portanto, nefasto sob o ponto de vista religioso do Hinduísmo]. A mente é cativa dos Kleśas. Suas modificações incessantes estão, em grande parte, ligados a isso. Egoísmo, desejo, ódio e medo dominam a vida mental, mal dandoIhe uma chance para discriminar a si mesmo. Assim, falhando por causa da ignorância em descobrir a sua fundação não intencional to purusa) carrega a ideia errônea sobre a natureza do eu: raiz do do Kleśa asmita [ignorância]. Este, por sua vez, envolve-se mais com as polaridades que são características do redemoinho de existência que é samsara. Virtude e vício, prazer e dor, e apego e aversão são os seis raios da roda de samsara. Transcendendo o papel psicológico e ético da vida mental, a descrição soteriológica emerge. A vida mental é percebida não apenas como uma teia de estados coloridos com aflições; estes são interceptados por aqueles que se opõem a esta tendência. Para usar o imaginário do Yoga, estes aklista vrttis (movimento da mente não causador do sofrimento) produzem brechas que podem orientar para o conhecimento discriminativo (viveka) e para a salvação.(BALSEV, 1991, p. 79) 
Em resumo, pode-se pensar que há emoções que deveriam ser cultivadas para ajudar diretamente na criação de um estado de espírito apropriado, portanto, ético sob o ponto de vista do ioga. Dispondo os kleśas como emoções, Balsev argumenta, a partir da sua interpretação do IS, que eles não seriam meramente consequências de uma ação, mas os principais responsáveis (motivações) pelas ações humanas, uma espécie de aspecto natural dos seres humanos ainda enredados na ilusão ou alienação da vida pautada na ética espiritual do ioga. Os kleśas não teriam, dessa forma, valores morais ou imorais, racionais ou irracionais, mas seriam ativamente propulsores de ações e responsáveis pela permanência dos homens e mulheres em samsāra, portanto, longe de samādhi - a experiência mística de comunhão com Deus. Balsev esclarece também que a mente no ioga seria espontaneamente cativa dos kleśas. Purusa, ou alma imaculada e perene - consequentemente não contaminada por prakrti ou corpo/emoções - é o objetivo do ioga. Samādhi, então, residiria no retorno da consciência, livre das perturbações emocionais dos kleśas, ao estado de equilíbrio/harmonia ou "homeostase" divino de purușa ou alma. Sendo a Ignorância ou alienação a matriz dos kleśas, a vida ética ioguica estaria na busca espiritual em conhecer a verdade que está por trás das perturbações mentais advindas dos kleśas (BALSEV, 1991).

Outro ponto ressaltado pela autora está não somente no pura e simples "cessar da mente", mas do cessar do fluir da mente presa na "direção" das emoções atreladas aos kleśas. Assim, é lícito supor que as práticas do ioga mais do que cessar a influência dos Kleśas, devem originar emoções opostas a estes, ou seja, do apegodesejo para o Desapego, da aversão-ódio para a Compaixão, do medo da morteAngústia para a Coragem em viver ou Alegria e do orgulho-egoísmo para a Humildade e Respeito. As práticas de ioga poderiam se configurar hoje como rituais de cura sobretudo das emoções deletérias associadas aos kleśas descritas por Balsev.

A partir dessa análise e das colocações de lyengar anteriormente, que associam os kleśas com doenças, a prática corporal moderna do ioga parece se tornar, mais do que uma aula de ginástica, um ritual exorcista das emoções do medo, do ódio, do desejo e do egoísmo Mas qual a relação está sendo estabelecida entre essas emoções/ kleśas apresentadas por Balsev, com a manifestação de doenças psicofísicas? 


\section{Kleśas e estresse}

Nas ciências da religião, pesquisas revelam a ocorrência do entrelaçamento entre doença-sagrado, medicina-religião e cura-salvação em diversas religiões (FULLER, 2008, p.131-152; LAPLANTINE, 2011, p.213-252). A cientista Sarah Strauss corrobora essas aproximações com o ioga moderno nos esclarecendo que no ioga moderno a doença seria uma espécie de sintoma a um sentir-se mal, angústia ou dor incorporada (STRAUSS, 2008), talvez um mal-estar. Dessa forma, é legítimo explorar o provável diálogo estabelecido, modernamente, entre as noções da experiência corporal do mal/angústia/dor e o conceito de estresse, popularizado nas sociedades urbanas como promotor de doenças.

Segundo R.T. Rao, mas corroborado por outros pesquisadores, os kleśas poderiam hoje estabelecer correspondência ao agente estressor ou estresse propriamente dito; e duhkhha (lit.dor), à experiência dolorosa ou o próprio sofrimento espiritual advindo dos nocivos comportamentos dos kleśas. O așthanga ioga $(A I)$ - os oito princípios espirituais do ioga clássico ${ }^{5}$ - por sua vez, poderia estar sendo reformado dentro da comunidade ioguica atual, como técnicas para dominar e eliminar tanto as emoções-kleśa quanto o estresse originado por essa dialética do mal-kleśas-doenças (BHAVANANI, 2007; RAO, 2012).

Essas observações - considerar o estresse como sinônimo de kleśa ou resultado de certas emoções deletérias à saúde -, por outro lado, nos fazem concluir equivocadamente que toda a manifestação fisiológica do estresse seria nefasta para a vida humana ou produtora do desejo, do ódio, do medo ou egoísmo - e ainda, considerar essas emoções sempre como moralmente condenáveis para a vida humana; o que é uma inverdade, ao menos não-científica. Todavia, o estresse especificamente, na perspectiva estrita da biologia, nunca foi compreendido assim. $\bigcirc$ estresse como sinônimo de doença é uma noção popularizada sem o devido respaldo da fisiologia biomédica e, talvez incorporada de alguma forma ao complexo sistema de crenças do ioga moderno.

Os Kleśas, como já adiantamos, até o surgir da modernidade, sempre foram sinônimo de cinco aflições espirituais responsáveis por perpetuar o estado de

${ }^{5}$ Yamas, Niyamas, Asanas, Prānayamas, Prathyahara, Dharana, Dhyana e Samadhi. 
servidão ou sofrimento humano em samsara (SCHONFELD, 2010). Assim, é plausível pensar nos comportamentos dos kleśas com outras conotações, como a resposta biológica ao estresse, a emoções nefastas, bloqueios energéticos transfisiológicos, contrações neuromusculares crônicas e manifestações de doença. Por força, talvez, da agitação das grandes cidades urbanas, local onde o ioga moderno se populariza, o estresse pode estar sendo associado como grande causador das moléstias do mundo, por isso, fonte das nefastas emoções de ódio, egoísmo, desejo e medo. Mas, o estresse causador de doenças é uma construção moderna e não surge da fisiologia biomédica, e muito menos das escrituras antigas ioguicas (mesmo porque o conceito surge apenas no século XX), mas sim de narrativas contemporâneas do senso-comum e incorporadas à religiosidade ioguica.

\section{Estresse biológico}

Em 1916, o fisiologista norte-americano Walter Cannon apresentou pela primeira vez o termo estresse na biologia, num artigo publicado na revista Nature. O seu intento estava em elucidar uma resposta fisiológica natural de emergência dos seres vivos, contida na sua hoje clássica, teoria de luta-ou-fuga (CANNON, 1927). Em 1932, o mesmo autor denomina de homeostase (homeo-stasis ou estado de equilíbrio] a capacidade do organismo em preservar um conjunto de mecanismos regulatórios que mantém a constituição do seu meio interno dentro de limites adequados para a sua sobrevivência, mas que são rompidos em situações estressantes ou na presença de um agente estressor, como hipoglicemia, um leão correndo para nos atacar ou uma fatura vencida por dificuldade financeira.

Assim, o conceito de homeostase reside em um estado psicofísico ideal, nunca alcançável, pois nosso organismo está a todo instante numa disputa intensa de busca pelo equilíbrio dinâmico de suas forças vitais, estado este (homeostase) só alcançado definitivamente, na morte. Quando acordamos por exemplo, depois de oito horas de sono, nossos níveis de glicose estão baixíssimos - o que denominamos de hipoglicemia - por isso, em desajuste fisiológico e longe dos níveis ideais de homeostase. A hipoglicemia aqui é o agente estressor e, por isso, aciona o eixo-doestresse e mecanismos fisiológicos regulatórios inatos entram em ação na busca por 
restaurar a harmonia ideal.

Nesse momento, até tomarmos o desjejum, a fisiologia humana busca mecanismos compensatórios ao agente estressor hipoglicemia. No estado estressante hipoglicêmico, o pâncreas inibe a secreção do hormônio insulina (responsável por transportar a glicose do sangue para as células] e aciona o seu antagonista, o hormônio glucagon. $\bigcirc$ glucagon secretado pelo pâncreas, por sua vez, se dirige ao fígado para degradar o glicogênio estocado e ofertá-lo na forma de glicose la sua menor parte molecular).

Quando esse processo atinge níveis satisfatórios de glicose circulante no sangue - detectados por quimioreceptores - o sistema nervoso central inibe o glucagon e aciona novamente o hormônio insulina a entrar em ação e transportar a glicose produzida para as células e reestabelecer os níveis glicêmicos aceitáveis deste sistema. Mas o processo continua pois, mesmo durante o desjejum a homeostase é rompida novamente, mas por outro sistema, o digestório. Na digestão o fígado precisará processar as proteínas, gorduras e carboidratos excedentes na forma de glicogênio para o fígado, aguardando um novo momento de hipoglicemia ou armazenando-o em forma de gordura adiposa.

Hans Seyle em 1936, concordou com Cannon, mas ampliou a concepção de estresse classificando-a em três fases distintas: 1) Alarme: quando o organismo reage instintivamente a um agente estressor qualquer na resposta de luta-fuga e rompe a sua homeostase, esse equilíbrio dinâmico do organismo; 2) Adaptativa: manifesta no momento em que organismo gera uma resposta satisfatória e "equilibra" novamente seu estado homeostático a níveis satisfatórios; e 3) Crônica: um estado em que a resposta fisiológica ao agente estressor não é suficiente para o organismo retomar o seu estado homeostático aceitável. Segundo Seyle e Cannon, mas ainda válido pela atual comunidade de fisiologistas científicos, seria somente na terceira fase (a crônica) em que o estresse, como resposta orgânica natural, poderia refletir negativamente sobre a saúde do organismo e, inclusive desenvolver respostas emocionais negativas a saúde do indivíduo, como o medo, a raiva, a fome e a dor (ver CANNON, 1927; SEYLE, 1976). Walter Cannon, logo, assim como os iogues segundo Balsev, também associou emoções com a manifestação do estresse, mas somente os segundos, construíram uma narrativa espiritual e o associou à "vida plena" ou a uma ética religiosa. 
Enquanto o estresse biológico é um estado fisiológico normal e neutro na fisiologia humana, na maior parte do tempo benéfico para a manutenção da vida, como quando nos preparamos para um jogging ou para enfrentarmos uma banca de defesa de doutorado; é somente em situações extenuantes e persistentes que ele é desvantajoso à saúde. $\bigcirc$ estresse ioguico, por outro lado, revelado por R.T. Rao e Bhavanani como sinônimo de kleśa, assim como os kleśas-emoções negativas de Balsev, trata-se de uma nova concepção criada no seio da religiosidade ioguica moderna. Há um hiato entre o que iogues e biólogos compreendem sobre a noção de estresse e emoções. Além disso, os iogues tendem a associar as manifestações psicofisiológicas de estresse e das emoções sem perder de vista as suas antigas crenças em corpos metafísicos e energias transfisiológicas como o demonstrei na subseção anterior, algo inadmissível no meio acadêmico. Entretanto, isso não deslegitima o discurso ioguico, enquanto lido como uma doutrina espiritual, e não como um texto pertencente a fisiologia biomédica científica.

O que saliento até aqui é a presença constante do estresse/agitação-Mal e da homeostase/equilíbrio-Bem atuando no teatro do corpo. Podemos afirmar que os iogues transplantaram da linguagem neutra da ciência fisiológica biomédica para a sua narrativa religiosa transfisiológica. Em outras palavras, há uma dialética homeostase - samādhi e estresse biomédico e estresse-ioguico se estabelecendo. Restituir-se ao estado de homeostase, no microuniverso ioguico adquiriu características de um estado fisiológico ideal e espiritualizado de "harmonia", homeostase eterno e divina ou relaxamento espiritual, estado místico similar ao samādhi.

\section{Relaxamento Espiritual}

Dois fatos interligados podem esclarecer melhor a contenda que busco expor entre o cenário aparentemente sereno que envolve o ioga e a ciência. A primeira diz respeito à resposta psicofisiológica do relaxamento que a ciência propala como resultado empírico dos ritos corporais ioguicos modernos, portanto, uma resposta "cientificamente" antagônica ao do estresse biológico, mas de estreita relação com a ideia de homeostase divina revelada anteriormente. $\mathrm{E}$ a segunda, reside na permanência da crença em energial vital, sobretudo prāṇa, entre os iogues 
modernos (FULLER, 2008, p.133-150; SAMUEL \& JOHNSTON, 2013). O relaxamento, resultado inequívoco das práticas ioguicas e aceito entre as tradições/métodos/instituições do ioga modernos - pois legitimado pela fisiologia ocidental e não pelas suas antigas escrituras - e a crença em uma fisiologia "sutill" ou transfisiologia são peças chaves na elucidação da questão kleśzestresse-emoçãoignorância e kaivalyathomeostase-conhecimento como novos bens de salvação ioguicos.

Walter Cannon alertava, ainda 1919, sobre as consequências fisiológicas que sofremos sob estresse, mesmo em estado natural de sobrevivência, não se tratando de estresse crônico. Ainda assim, o processo digestivo, por exemplo, sofreria forte influência quando - ainda que mentalmente, e não apenas de forma ambiental manifestamos certas emoções inatas. Isso significa que, quando com raiva, medo, fome e dor, o corpo reage também com a mesma resposta fisiológica do estresse, pois representam para o organismo - por milhares de anos de evolução humana emoções acionadas a eminência da morte (CANNON, 1927). Sabemos hoje, pelas mais recentes pesquisas em psicologia cognitiva, que possuímos emoções primárias: raiva, medo, surpresa, nojo/aversão/desprezo, prazer/alegria e tristeza/angústia que acionam contrações musculares específicas (REICH, 1989; Id., 1992; DAVIDSON, 1990), deste modo, há um complexo sistema psicofisiológico envolvido em nossos pensamentos, comportamentos e construções mentais (LAKOFF \&JOHNSON, 1999; KANDEL, 2003; FULLER, 2008). Desta forma, respostas emocionais acionadas por gatilhos de agentes estressores (seja mentais ou físicos) geram as mesmas respostas do estresse (conscientes ou não) e, por conseguinte, contrações musculares que podem se tornar crônicas. Estas contraturas musculares crônicas podem ocasionar dores permanentes, invariavelmente, de origem emocional. Técnicas de relaxamento, como massagens, alongamentos, exercícios respiratórios e até psicanálise podem atenuar essas dores trazendo à consciência o conteúdo emocional (inconsciente) latente.

Neil Jacobson, ainda em 1932, já compilava em seus livros títulos imperativos como You Must Relax: Practical Methods for Reducing the Tensions of Modern Living, aonde alertava sobre a necessidade do momento de relaxamento para as tensões ocasionadas pela vida moderna. Ele construiu teorias importantes sobre os "Nervos da Guerra", por exemplo, devido a sua preocupação com o medo que 
assombrava a sua época pós-guerra, ou o excesso de estresse sofrido por aqueles que passavam horas trabalhando em hospitais de guerra e cuidando de soldados feridos (JACOBSON, 1934).

Petho Sandor, médico húngaro que desenvolve o método terapêutico do toque sutil e leciona na Pontíficia Universidade Católica de São Paulo (PUC-SP) nas décadas de 50-60, percebeu enquanto tocava partes do corpo durante o atendimento em feridos da segunda grande guerra, uma benéfica resposta ao relaxamento. Assim, desenvolveu seu método psicoanalítico, no qual o relaxamento ocupa uma posição de destaque em suas obras de psicologia. Ele analisou as comutações dos processos fisiológicos associados ao relaxamento: suas autoregulações psicofisiológicas, aquisição e manutenção de memórias, mas sobretudo, em como os processos de relaxamento atuam sobre a afetividade humana. $\bigcirc$ resultado clínico, segundo o autor, além do descanso em nível fisiológico de equilíbrio orgânico, atinge processos inconscientes que auxiliam na introspecção dos pacientes a reproduzir de forma construtiva antigas vivências, emoções e sentimentos, promovendo assim, novas coordenações e estruturações psicobiológicas (SANDOR, 1974).

método de Sandor pretende, pelo relaxamento progressivo, conduzir o paciente a experimentar "um outro modo de relacionamento consigo mesmo e com o mundo circundante, e a enfrentar as tensões que lhe eram pouco conscientes" (Ibid., p.13). Por influência das couraças neuromusculares do caráter de W.Reich e da "energia psíquica" de Gustav Jung - dentre outros -, o autor visa pelo relaxamento, o paciente a reviver e a experimentar as situações que o angustiam, para que assim, "seja expectador de suas próprias vivências internas desatando ao mesmo tempo certas inibições, principalmente corticais, que podem se manifestar como crítica, ceticismo e intelectualização exagerada." (Ibid.). Através de sessões psicoterapêuticas de relaxamento Sandor analisou as narrativas dos seus pacientes "nestes estados oníricos", como ele se referia à experiência sensorial que os conduzia. Ele percebeu que o contato corporal realizado com seus pacientes, durante esses estados, possibilitava a eles tomarem decisões assertivas em suas vidas, como comentado abaixo:

Vimos através da exposição [comentada extensivamente por Sandor 
em seu livro com pormenores cada conteúdo inconsciente resgatado durante as suas sessões de relaxamento], como [a paciente] entrou em uma longa e ininterrupta série de mutações e como no processo de liberação vem adquirindo a função diretora [da sua vida]. Transfere para si a responsabilidade de auto-direção, e notamos que assumindo-a, está ampliando sua consciência. Assim tornam-se conscientes os conteúdos em virtude da apropriação, assimilação, transformação dos elementos até então inconscientes. Isto significa um aumento e extensão do nível de integração, organização e utilização sempre mais produtiva, do próprio dinamismo psíquico (Ibid., p.18).

Assim como o ioga no Brasil o fará modernamente, o relaxamento aqui ganha contornos de uma técnica psicoterapêutica de acesso ao inconsciente e de um "processo de liberação" e com o poder de "ampliar a consciência". A prática psicoterapêutica corporal conduzida por Sandor em seus experimentos com o relaxamento conquista um sentido de "integrar, organizar e utilizar" o conteúdo inconsciente reprimido para ganho de maior "dinamismo psíquico".

Defendo que a corporificação e medicalização do ioga moderno é um desenvolvimento de uma tradição de ioga surgida na Índia medieval, o hatha-ioga, de forte influência religiosa do tantrismo, da medicina ayurveda e da mística islâmica (FIELDS, 2001; SIMÕES, 2015). O relaxamento no ioga contemporâneo como parte indissociável e importante no processo que acompanha qualquer prática atual é, de outro modo, fruto também da influência de outros métodos de autoconhecimento como descrevemos acima; um desenrolar da própria dinâmica do ioga na sua transplantação aos modernos centros urbanos do mundo e suas culturas.

A partir da década de trinta, publicações de divulgação científica em fisiologia e biomedicina preocuparam-se em como atenuar as angústias advindas do terror das duas grandes guerras mundiais e das atribulações cada vez maiores dos trabalhadores dos centros urbanos que, a partir da revolução industrial, convivem com novos agentes estressores, como a crescente violência das grandes cidades e do estilo de vida capitalista e consumista. Os iogues modernos, dentro deste contexto, alcançam popularidade entre os meios alternativos das sociedades ocidentais ${ }^{6}$, desejosos de transformação social frente a este novo panorama social, político, econômico e

${ }^{6}$ The wisdom of the body: How the human body reacts to disturbance and danger and maintains the stability essential to life de Walter B. Cannon (1932); The Relaxation Response de Herbert Benson (1975); You Must Relaxatiorr. Practical Methods for Reducing the Tensions of Modern Living de Neil Jacobson (1976), e Stress in the health and disease de Hans Seyle (1976). 
religioso. Novas terapias, como o ioga, são trazidas como "alternativas" e descobrese meios terapêuticos advindos da espiritualidade Nova Era de baixo custo que poderiam ser estendidos a grandes populações.

Herbert Benson, através dos estudos preliminares de Walter Cannon, Jacobson, Seyle e Sandor, desenvolve a hipótese que, se nascemos dotados de um eixo do estresse para lutar ou fugir da raiva, medo, fome, dor e outras emoções "gatilhos" do estresse, deveríamos também possuir um outro processo fisiológico antagônico a este, um "eixo fisiológico" responsável por reestabelecer o organismo ao estado de homeostase, ao seu "estado natural". A este eixo fisiológico, antagônico a manifestação do estresse, o Benson denominou de resposta do relaxamento, tese esta defendida em seu principal livro The Relaxation Response, com cursos ministrados na Universidade de Harvard até os dias atuais. Concomitantemente, os trabalhos de Herbert Benson (ver BENSON, 2000) difundiram as práticas corporais advindas do ioga como promotores à saúde pela resposta do relaxamento promovidas por elas, impulsionando a crença moderna do ioga como terapia de combate ao estresse e suas correspondentes emocionais. No entanto, a questão aqui reside em compreender por quê toda a fundamentação científica da fisiologia biomédica descrita até aqui, que deveria desencantar, por assim dizer, o ioga parece, ao contrário, legitimá-lo como um novo caminho espiritual em meio a sociedades laicas e fundadas pela razão das ciências empíricas.

\section{Profanação do ioga ou reforma de seus antigos bens de salvação?}

Com a imbricação do ioga com o racionalismo e o empirismo da ciência moderna, o conceito religioso de prāṇa como energia vital, ao invés de desencantarse, se ressignifica e ganha existência "empírica" a partir do Mesmerismo de Franz Mesmer e do conceito de orgone e das couraças neuromusculares do caráter desenvolvidos na psicologia de W. Reich ao microuniverso ioguico moderno (SINGLETON, 2005; SAMUEL \& JOHNSTON, 2013). O psicólogo da religião William James ainda no início dos anos de 1900, e Robert Fuller atualmente, revelam que é a fé na existência metafísica da energia corpórea a responsável pelos iogues atuais, e os religiosos investigados por James no início de 1900, perceberem as 
doenças que acometem os seres humanos como um tipo de desequilíbrio energético sutil, transfisiológico ou metafísico (JAMES, 1995, p.59-88; FULLER, 2008, p.133; p.143-144), Em outras palavras, na ação do demônio, e por isso as suas práticas purificadoras de exorcizar o mal/ kleśas, como já descrevemos.

Os kleśas, originalmente comportamentos pautados nos ditames hinduístas e consagrados por Patanjali, de influência religiosa Samkhya, contemporaneamente vêm ganhando interpretações mais corporificadas como demonstramos. Prāṇa - a energia transfisiológica do ioga medieval - exerce papel fundamental na permanência dos kleśas como causa do mal associado ao estresse e emoções nefastas. Sua função - de prāṇa - reside como ponte entre o empírico da ciência fisiológica atual e a metafísica da transfisiologia ioguica. Em outras palavras, quando o ioga encontra as sociedades seculares, onde a religião institucional compete com a ciência como originadora de sentidos de vida, cria-se uma necessidade de tornar sensível o que antes estava circunscrito ao mundo suprassensível de acesso exclusivo de sacerdotes e místicos hinduístas.

Atualmente, as práticas ioguicas desenvolveram um caráter duplo de purificação corpórea - fisiológico e "sutil" -, mas o foco dos iogues modernos permanece na obtenção do livre fluir de prāna em seus corpos, onde as doenças não os alcançam pois, em última análise, seus corpos são purificados a cada prática ritual que realizam. Deixar de praticar seus rituais corpóreos diários (seja na recitação de mantras ou execução de 108 sūrya namaskara) é permitir que o mal/kleśas se manifestem em seus corpos e obstruam as suas fisiologias ["sutis" e físicas] do livre fluir de energia vital prânica.

Como vimos em outras citações, é fundamental a crença em energias transfisiológicas por dois motivos: primeiro por permitir que os praticantes de ioga possam, eles mesmos, sentir a atuação dos kleśas/Mal, pois a obstrução dos canais energéticos no corpo faz com que surjam doenças, cansaço e fadiga, causas encarnadas da atuação nefasta dos kleśas. Segundo, mantendo a crença em prāṇa, retira-se do saber científico - portanto dos cientistas - qualquer possibilidade de secularizar o ioga. Em suma, sendo o prāṇa real, sob o ponto de vista da fisiologia religiosa do ioga, reserva-se apenas aos mestres ioguicos a manipulação de força vital na eliminação do sofrimento humano. Os cientistas podem investigar as repercussões fisiológicas da sua biomedicina, mas a cura dos Kleśas, apenas aos iogues se conserva 
esse poder.

Essa corporificação, seja como manifestação de doença ou em componentes emocionais, deslegitimou em certa medida as escrituras antigas do ioga, privatizando a sua análise pelos próprios iogues. Os líderes ioguicos, com isso, perceberam a perda gradual de autoridade sobre a sua comunidade, em detrimento do saber crescente da ciência biomédica sobre o seu grupo. Reformaram, assim, a causa do mal ioguico sob o manto da ciência e caminharam (ainda em processo) para o afastamento da religião hinduísta, erigindo os contornos do ioga com uma religiosidade própria e distinta, longe, tanto da nebulosa Nova Era, quanto da ortodoxia hinduísta. Este afastamento dos textos vedantinos e das escrituras clássicas do ioga enseja, a alguns cientistas e adeptos, um certo estranhamento ou desconforto, como se estivesse havendo uma profanação da sua espiritualidade "original".

\section{Conclusão}

Mark Singleton se aprofunda neste tema, tendo como marco teórico o artigo $A$ salvação pelo relaxamento de W. James, e demonstra que o rótulo de "combate ao estresse" que as práticas do ioga moderno conquistaram, seriam consequência da imbricação do ioga com as terapias proprioceptivas ocidentais, e não de sua origem hinduísta de comunhão com Deus/Isvara, como exposta no IS e discutidas nas subseções anteriores. Segundo ele, o ioga em contato com o estilo de vida agitado das grandes cidades do mundo ocidental teria direcionado a sua salvação para o relaxamento. Esse fato poderia revelar uma corrupção da ancestralidade espiritual do ioga em detrimento a uma coletividade que não descansa, contribuindo dessa forma, com a ideologia capitalista do consumo e do trabalho (SINGLETON, 2005).

Não há dúvidas que o ioga moderno enveredou, como já expomos, para sua medicalização e as suas práticas como técnicas profanas em muitos setores da saúde. Por outro lado, pesquisas apontam igualmente que nunca existiu um "ioga puro", e a tradição de ioga do seu período medieval - o hatharioga - seria a responsável (e não o estilo de vida moderno] pela maior valoração dada ao corpo em detrimento às suas escrituras clássicas (LIBERMAN, 2008, p.113).

Assim, a influência social capitalista desenvolveu, sem dúvidas, no florescer 
do relaxamento como "produto" contemporâneo mais importante revelado pelo ioga. E a ciência, não o IS (Yoga Sūtra), é a base intelectiva para isso ocorrer. No entanto, ao contrário do que Singleton pensa, este fato poderia refletir não uma corrupção dos preceitos espirituais ioguicos clássicos, mas também uma reforma soteriológica legítima dos seus antigos bens de salvação. A proposta de salvação ioguica, antes pautada exclusivamente nos ensinamentos hinduístas dos kleśas e samādhi, perdeu o seu sentido religioso em meio a sociedades secularizadas e privatizadas religiosamente. Reflexo disso são os debates que ocorrem discutindo se o ioga de Patanjali teria mesmo influência do hinduísmo, ou se seria fruto de um sincretismo de outras religiões como o Budismo (NICHOLSON, 2013).

que podemos resumir da nossa discussão neste artigo, é a conotação que os kleśas assumiram no ioga moderno. A partir de 1915, fisiologistas ocidentais descobrem e nomeiam uma resposta orgânica natural acionada na raiva, no medo, na fome e na dor, que denominaram de resposta de luta-fuga, a qual aciona o eixo psicofisiológico do estresse e rompe com o equilíbrio do organismo, a homeostase. Mais tarde, os mesmos fisiologistas julgaram haver uma igual explicação fisiológica inata, mas oposta a do estresse que denominaram de reposta do relaxamento. Criouse aí uma polaridade do estresse-Mal-sofrimento e do relaxamento-Bem-cura como uma experiência, mesmo que transitória, do Bem no microuniverso espiritual do ioga moderno. A reforma religiosa do samādhi em homeostase divina como novo bem de salvação, seria um estado fisiológico ideal, utópico, portanto, transfisiológico.

Os iogues indianos quando transplantaram sua espiritualidade para as grandes cidades ocidentais já encontraram esse panorama social e cultural de "vida agitada" e do capitalismo de consumo e, talvez, ao invés de "profanar" e "desencantar" os seus rituais corporais, apenas se adaptaram e ajustaram a sua fisiologia religiosa a este novo contexto biopsicocultural. Admitindo esses fatos, nos é lícito supor porquê os kleśas assumiram a responsabilidade de causa do estresse-ioguico, e o samādhi - a experiência mística e transitória alcançada ao final das práticas rituais do ioga envolveu-se com o relaxamento, de forma a adquirir características espirituais e divinas. 


\section{Referências Bibliográficas}

ALTER, J. Yoga in Modern India: The Body between Science and Philosophy. New Jersey: Princeton University Press. 2004.

ARANYA, H.S. Yoga philosophy of Patanjali. New York: State University of New York Press. 1983.

BALSEV, A.N. The Notion of Kleśa and Its Bearing On the Yoga Analysis of Mind. Philosophy East and West. 41(1): 77-88. 1991.

BENSON, H. The relaxation Response. New York: Harpertorch. 2000.

BERRY, T. Religions of India: Hinduism, Yoga, Buddhism. Chambesburg: Anima Publications. 1992.

BHAVANANI, A.B. A yogic approach to stress. 2a. Edição. Puducherry: Dhivyananda Creations. 2007.

BOURDIEU, P. A produção da crença: Contribuição para uma economia dos bens simbólicos. 3a. edição. Porto Alegre: Editora Zouk. 2001.

CANNON, W.B. Bodily changes in pain, hunger, fear and rage. New York: D. Appleton \& Cia. 1927.

CHAMPION, F. Les Sociologues de La post-modernité religieuse et La nébuleuse mystique-ésoterique. Archives de Sciences Sociales des Religions, 67(1): 155-165. 1989.

DAVIDSON, R.J.; EKMAN, P.; SARON, C.D.; SENULIS, J.A. \& FRIESEN, W.V. Approach-withdrawal and cerebral asymmetry: emotional expression and brain physiology. Journal of Personality and Social Psychology, 58: 330-341. 1990.

DeMICHELIS, E. A history of modern yoga: Patañjali and Western Esotericism. London: Continuum Books. 2004.

FERNANDES, E. \& DA ROCHA, V.M. A imagem do yoga como terapia e como ginástica: Uma construção ocidental. Vivência Artigos. 29: 311-326. 2005.

FIELDS, G.P. Religious Therapeutics: Body and Health in Yoga, Ayurveda and Tantra. Albany: State University of New York Press. 2001.

FULLER, R.C. Spirituality in the flesh: Bodily sources of religious experience. New York: Oxford University Press. 2008.

GNERRE, M.L.A. Identidades e paradoxos dos yoga no Brasil: Caminho espiritual, 
prática de relaxamento ou atividade física? Fronteiras. 12(21): 247-270. 2010.

GULMINI, L.C. O Yoga Sūtra, de Patanjali: Tradução e análise da obra, à luz de seus fundamentos contextuais e linguísticos. Dissertação de Mestrado, Área de Semiótica e Linguística Geral da Universidade de São Paulo. 2002.

IYENGAR, B.K.S. A árvore do ioga: a eterna sabedoria do ioga aplicada à vida diária. São Paulo: Editora Globo. 2001.

; EVANS, J.J. \& ABRAMS, D. Light on life: The Yoga Journey to Wholeness, Inner Peace and Ultimate Freedom. United States of America: Holtzbrinck Publishers. 2005.

Editorial. 2007. Luz na Vida: A jornada do ioga para a integridade. Summus

HANEGRAAFF, W. New Age spiritualities as secular religion: a historian's perspective. Social Compass, 46(2): 145-160. 1999.

Religion, 33: 357-380. 2003.

How magic survived the disenchantment of the world.

JACOBSON, E. You Must Relax: Practical Methods for Reducing the Tensions of Modern Living. Chicago: Mcgraw-Hill. 1934.

JAIN, A. Selling yoga: from counterculture to pop culture. New York: Oxford University Press. 2014.

JAMES, W. As variedades da experiência religiosa: Um estudo sobre a natureza humana. São Paulo: Editora Cultrix. 1995.

KAELBER, W.O. Tapta Marga: Ascetism and initiation in vedic India. Albany: State University of New York Press. 1989.

KANDEL, E.R.; SCHARTZ, J.H. \& JESSEL, T.M. Princípios da Neurociência. São Paulo: Ed.Manole. 2003.

LAKOFF, G. \& JOHNSON, M. Philosophy in the flesh: The embodied mind and its challenge to western thought. New York: Basic Books. 1999.

LAPLATINE, F. Antropologia da doença. São Paulo: Martins Fontes. 2011.

LIBERMAN, K. The Reflexivity of the Authenticity of Hatha Yoga. In: SINGLETON, M. \& BYRNE, J. (orgs.) Yoga in the Modern World, Contemporary Perspectives. London: Routlege, p.100-116. 2008.

NEWCOMBE, S. Spirituality and 'Mystical Religion' in Contemporary Society: A Case Study of British Practitioners of the lyengar Method of Yoga. Journal of Contemporary Religion. 20(3). 2005. 
NICHOLSON, A.J. Is yoga hindu? On the fuzziness of religion boundaries. Common Knowledge, 19 (3): 490-505. 2013.

NUNES, T.C.L. Yoga: Do corpo, a consciência; Do corpo à consciência: O significado da experiência corporal em praticantes de Yoga. Dissertação de Mestrado, Programa de Pós-Graduação em Antropologia Social da Universidade Federal de Santa Catarina. 2008.

RAO, R.T. Stress management throught yoga and yogic diet. International Journal of Multidiscplinary Educational Research. 1(3): 123-130. 2012.

REICH, W. Análise do caráter. São Paulo: Livraria Martins Fontes Editora. 1989. . A função do orgasmo. 17ª Edição. São Paulo: Editora Brasiliense. 1992.

SAMUEL, G. \& JOHNSTON, J. [orgs.) Religion and the subtle body in Asia and the West: Between mind and body. New York: Routledge Studies in Asia Religion and Philosophy. 2013.

SANDOR, P. Técnicas de relaxamento. São Paulo: Ed. Vetor. 1974.

SARBACKER, S.R. The numinous and cessative in modern yoga. In: SINGLETON, M. \& BYRNE, J. [orgs.] Yoga in the Modern World, Contemporary Perspectives. London: Routlege, p.161-183. 2008.

SCHONFELD, M. Yoga. In: LEEMING, D.A.; MADDEN, K. \& MARLAN, S. (eds.) Encyclopedia of psychology and religion. Springer, p.987-990. 2010.

SEYLE, H. Stress in the health and disease. New York: Butterworth. 1976.

SIEGEL, P. Yoga e saúde: $\bigcirc$ desafio da introdução de uma prática não-convencional no SUS. Tese de Doutorado, Programa de Pós-Graduação em Saúde Coletiva, da Faculdade de Ciências Médicas da Universidade Estadual de Campinas. 2010.

SIMÕES, R.S. O papel dos kleśas no contexto moderno do ioga no Brasil: Uma investigação sobre os possíveis deslocamentos da causa do mal e da produção de novos bens de salvação por meio da fisiologia biomédica ocidental. Tese de Doutorado, Programa de Pós-Graduação em Ciências da Religião da Pontifícia Universidade Católica de São Paulo. 2015.

SINGLETON, M. Salvation through Relaxation: Proprioceptive Therapy and its Relationship to Yoga. Journal of Contemporary Religion. 30(3): 289-304. 2005.

. The classical reveries of Modern Yoga: Patañjali and Constructive Orientalism. In: SINGLETON, M. \& BYRNE, J. [orgs.). 2008. Yoga in the Modern World, Contemporary Perspectives. London: Routlege, p.77-99. 2008.

SMITH, B.R. "With heat even iron willbend": Discipline and authority. In: 
SINGLETON, M. \& BYRNE, J. (orgs.) Yoga in the Modern World, Contemporary Perspectives. London: Routlege, p.161-183. 2008.

STRAUSS, S. Adapt, Adjust, Accommodate: the Production of Yoga in a Transnational World. In: SINGLETON, M. \& BYRNE, J. (orgs.) Yoga in the Modern World, Contemporary Perspectives. London: Routlege, p.49-74. 2008.

WEBER, M. A ética protestante e o espírito do capitalismo. São Paulo: Centauro. 2001. 